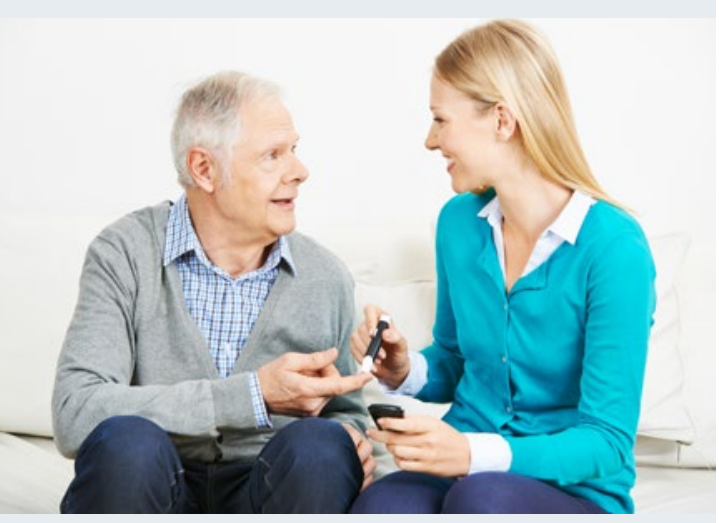

9 Diabetes im Alter

Diabetes ist eine Volkskrankheit. Und: Die Mehrzahl der Betroffenden befindet sich bereits in fortgeschrittenem Lebensalter. Grund genug das Augenmerk auf die besonderen Bedürfnisse älterer Diabetiker zu lenken.

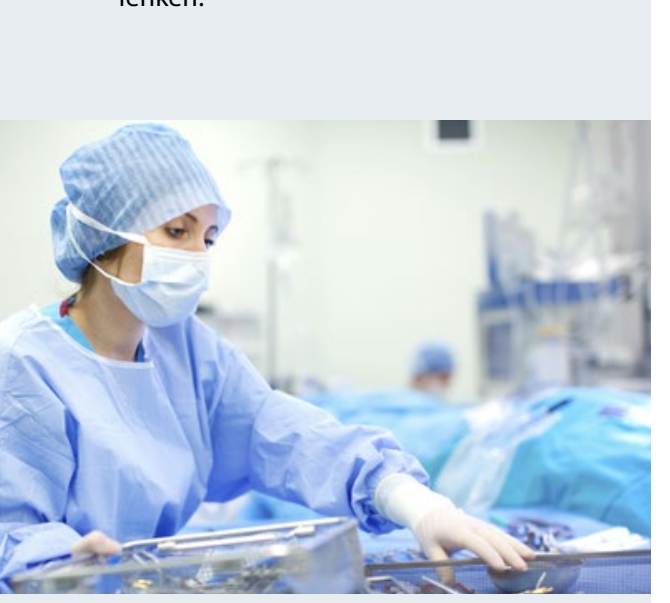

\section{Pflege bei Bypass-OP}

Operationen am Herzen sind eine Herausforderung für das ganze Behandlungsteam. Das gilt auch für die prä- und postoperative Pflege. Worauf kommt es dabei an und wie können die Patienten unterstützt werden? Das erläutert Petra Sorgenfrei vom Deutschen Herzzentrum Berlin.

\title{
PflegeAktuell
}

6

PflegeKolleg

Die zertifizierte Fernfortbildung für alle Pflegenden

So nehmen Sie teil

\section{PflegeKolleg Diabetes im Alter}

10 Wenn Diabetes auf die Blase geht Dranginkontinenz und Harnretention

14 Ängste ausräumen - Insulintherapie umsetzen Therapiehindernis Nadelphobie

16 Diabetes-Akutkomplikationen: Symptome richtig deuten Hypo- und Hyperglykämie

19 Fragebogen „Diabetes im Alter"

\section{PflegeKolleg Koronare Herzkrankheit}

\section{Bypass, Stent oder Pillen?}

Therapieoptionen bei verengten Herzkranzgefäßen

28 Pflege bei Bypass-OP

Informieren, Begleiten, Mobilisieren

31 Was darf ich? Kann ich?

Checkliste für Patienten nach Herz-OP

34 Zurück ins Leben nach Herz-OP

Patientenedukation und Genesungsprozess

37 Fragebogen „Koronare Herzkrankheit“

\section{Tipp}

Aktuelle Informationen aus dem Bundesverband Lehrende Gesundheitsund Sozialberufe e.V. (BLGS) finden Sie im Newsletter ab Seite 53

"Gemeinsam Bildung gestalten"

\section{So erreichen Sie uns:}

Redaktion HEILBERUFE

Springer Medizin Verlag GmbH

Heidelberger Platz 3

14197 Berlin

Tel.: 030827875500

heilberufe@springer.com

www.heilberufe.de
Kongressorganisation

Springer Medizin Verlag GmbH

Heidelberger Platz 3

14197 Berlin

Tel.: 030827875510

andrea.tauchert@springer.com www.gesundheitskongresse.de 
PflegePraxis

\section{Journal Club}

Aktuelle Studien für Sie gelesen

\section{Psychologie}

Der alternde Mann: Gesund bleibt, wer schwach sein kann

\section{PflegeAlltag}

\section{News}

\section{Integration}

Die Begeisterung der Kinder steckt an

Generationen übergreifende Betreuung

46 Nachgefragt bei Thomas Dewor

\section{Recht}

Heißes Wasser - ausgehängte Türen

Wer haftet bei Verkehrssicherungspflichten?

\section{PflegeKarriere}

\section{News}

50 Pflegedienst im Porträt

Psychiatrischer Pflegedienst

KAP betreut Menschen im Ausnahmezustand

53 Gemeinsam Bildung gestalten

Der Newsletter des Bundesverbandes

Lehrende Gesundheits- und Sozialberufe e.V. (BLGS)

\section{PflegeSchüler}

Demenzpflege auf den Philippinen

Mein Wahleinsatz im Inselparadies

\section{PflegePositionen}

61 Der Newsletter des Deutschen Pflegerates 11/2015

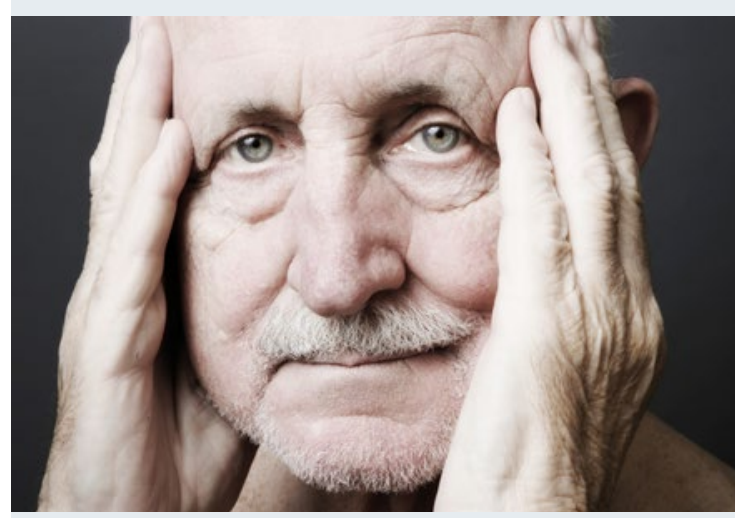

38 Nichts für Feiglinge ...

Vielen Männern fällt es schwer, das eigene Altern zu akzeptieren. Prostatabeschwerden und Co. passen so gar nicht zum eigenen Bild vom starken Geschlecht. Wenn Pflegende die Gesundheit von alternden Männern erhalten wollen, müssen sie auf dieses Rollenverständnis achten.

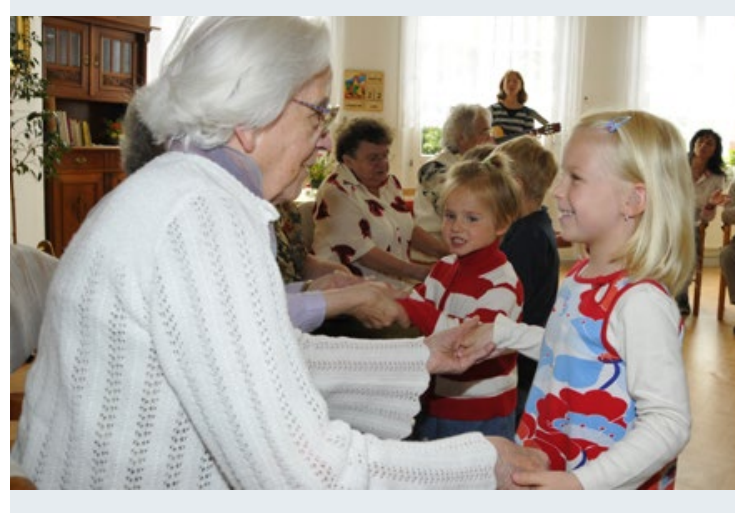

\section{Generationen übergreifend}

Eine Begegnung zwischen den Generationen ist für alte Menschen und Kinder gleichermaßen bereichernd. Und nicht nur das. Im Augusta-Viktoria-Stift in Erfurt lassen sich die positiven Effekte auf Lebensfreude und Aktivitäten der Senioren bereits seit Jahren beobachten.

\begin{tabular}{|c|c|}
\hline \multicolumn{2}{|c|}{ Rubriken } \\
\hline 65 & Termine \\
\hline 66 & PflegeMarkt News \\
\hline 68 & Stellenmarkt \\
\hline 72 & Gewinnspiel \\
\hline 74 & Prominente Patienten \\
\hline 75 & Impressum | Vorschau \\
\hline
\end{tabular}

\section{Titel}

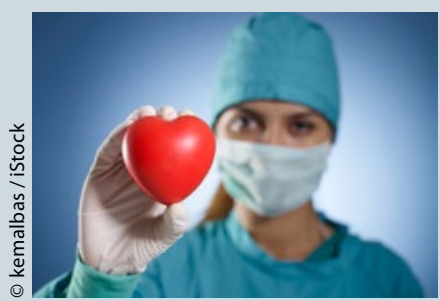

